УДК 547.918:547.458.68:543.42:661.167.7:581.142

\title{
МОЛЕКУЛЯРНЫЕ КОМПЛЕКСЫ ТРИТЕРПЕНОВЫХ ГЛИКОЗИДОВ ПЛЮЩА С $\beta$-ЦИКЛОДЕКСТРИНОМ
}

\author{
(C) Л.А. Яковишин
}

\author{
Севастопольский национальный технический университет, \\ ул. Университетская, 33, Севастополь, 299053 (Россия), e-mail: \\ chemsevntu@rambler.ru
}

Получены молекулярные комплексы тритерпеновых гликозидов $\alpha$-хедерина $(3-O-\alpha-L$-рамнопиранозил-( $1 \rightarrow 2)$ $O$ - $\alpha$ - $L$-арабинопиранозида хедерагенина) и хедерасапонина $C \quad(3-O-\alpha-L$-рамнопиранозил-(1 $\rightarrow 2)-O-\alpha-L$-арабинопиранозил-28- $O-\alpha-L$-рамнопиранозил- $(1 \rightarrow 4)-O-\beta-D$-глюкопиранозил- $(1 \rightarrow 6)-O-\beta-D$-глюкопиранозида $\quad$ хедерагенина) с $\beta$-циклодекстрином. Комплексообразование исследовано методом ИК-Фурье-спектроскопии. Рассмотрены токсические свойства молекулярных комплексов.

Ключевые слова: тритерпеновые гликозиды, $\alpha$-хедерин, хедерасапонин $\mathrm{C}, \beta$-циклодекстрин, молекулярный комплекс, ИК-Фурье-спектроскопия, токсичность.

Работа выполнена при финансовой поддержке РФФИ (проект 14-43-01031 p_юг_а).

\section{Введение}

К настоящему времени накоплены многочисленные данные о возможности получения новых лекарственных препаратов за счет клатрирования фармаконов глицирризиновой кислотой (3-O- $\beta-D$ глюкуронопиранозил-( $1 \rightarrow 2)-O-\beta-D$-глюкуронопиранозидом глицирретиновой кислоты), выделенной из различных видов солодки Glycyrrhiza L. [1-3]. В качестве молекулярных носителей различных лекарственных веществ предложены тритерпеновые гликозиды $\alpha$-хедерин (3-O- $\alpha$ - $L$-рамнопиранозил-( $1 \rightarrow 2)-O-\alpha-L$ арабинопиранозид хедерагенина, гликозид 1) и хедерасапонин $C$ (3-O- $\alpha-L$-рамнопиранозил- $(1 \rightarrow 2)-O-\alpha-L-$ арабинопиранозил-28-O- $\alpha$ - $L$-рамнопиранозил- $(1 \rightarrow 4)-O-\beta-D$-глюкопиранозил- $(1 \rightarrow 6)-O-\beta-D$-глюкопиранозид хедерагенина, гликозид 2) [4]. Гликозиды 1 и 2 являются главными сапонинами различных видов плюща Hedera L. [5] и входят в состав лекарственных препаратов на основе листьев плюща обыкновенного Неdera helix L., которые используются для лечения инфекционно-воспалительных заболеваний органов дыхания, сопровождающихся кашлем [5-7].

Начато изучение молекулярных комплексов тритерпеновых гликозидов с различными циклодекстринами $[8,9]$. В предыдущей работе мы сообщали о комплексообразовании $\beta$-циклодекстрина (3) с моноаммонийной солью глицирризиновой кислоты (глицирамом) [10]. Комплексы циклодекстринов с сапонинами плюща не описаны, поэтому настоящая статья посвящена ИК-спектроскопическому исследованию комплексов 3 с гликозидами 1 и 2 , а также анализу их биологической активности.

\section{Экспериментальная часть}

Гликозиды 1 и 2 выделяли из листьев плющей крымского Hedera taurica Carr. и канарского Hedera canariensis Willd. (Araliaceae Juss.) и подтверждали их строение, как описано в работах [11, 12]. Использовали образец 3 («Acros Organics», США), который предварительно сушили до постоянного веса при 50-80 ${ }^{\circ} \mathrm{C}$ в течение 3 ч. Комплексы препаративно получали путем смешивания растворов, содержащих по 1 ммоль 3 и гликозидов 1 и 2 (растворитель - смесь 70\% водного раствора этанола и хлороформа в соотношении 3:1, по объему).

Яковишин Леонид Александрович - доцент кафедры физики (цикл химии), кандидат химических наук, тел.: (0692) 43-51-06, e-mail: chemsevntu@ rambler.ru
Полученные смеси выдерживали при $40^{\circ} \mathrm{C}$ в течение 1,5 ч при постоянном перемешивании. Органические растворители отгоняли в вакууме. 


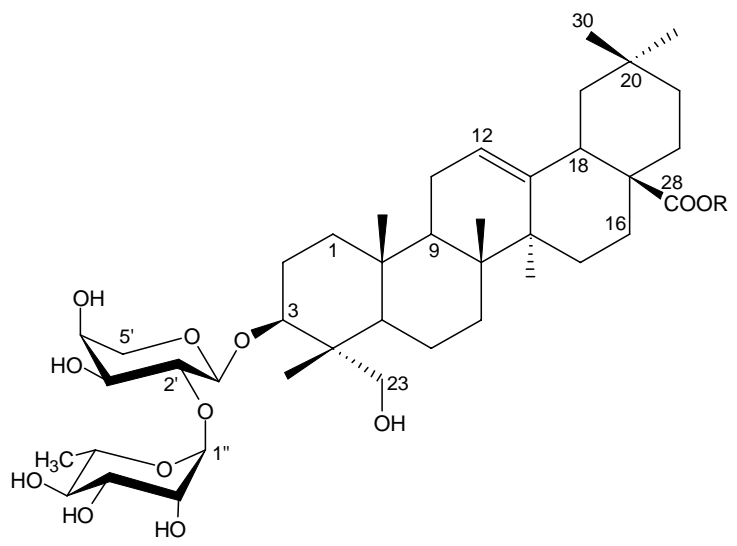

Гликозид 1: R=H

Гликозид 2: $\mathrm{R}=\leftarrow \beta \mathrm{Glc}_{p}-(6 \leftarrow 1)-\beta \mathrm{Glc}_{p}-(4 \leftarrow 1)-\alpha \mathrm{Rha}_{p}$.

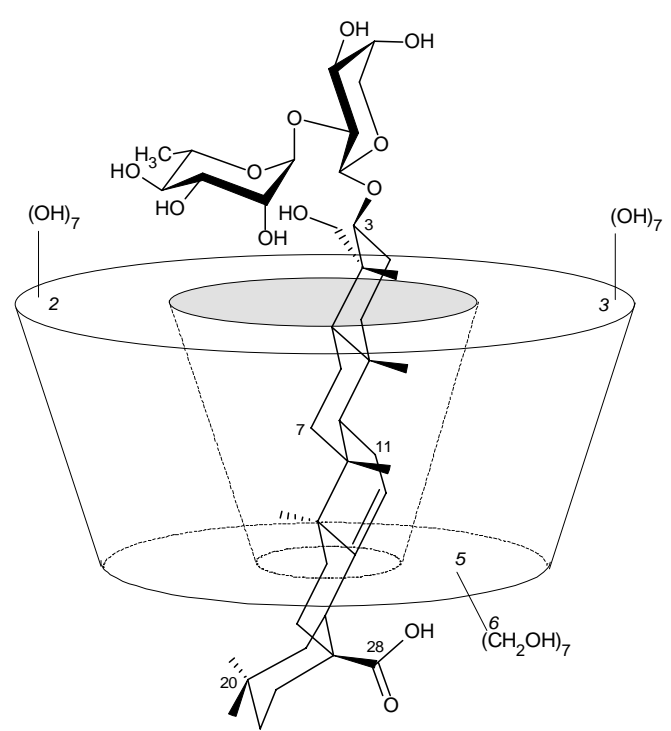

Комплекс гликозида 1 с 3

ИК-спектры сняты на ИК-Фурье-спектрометре ИнфраЛЮМ ${ }^{\circledR}$ ФТ-02 (Россия) в суспензии в вазелиновом масле при разрешении $1 \mathrm{~cm}^{-1}$ в диапазоне 4000-400 $\mathrm{cm}^{-1}$.

ИК-спектр 1 (вазелиновое масло, $v$, см$\left.^{-1}\right): 3360\left(v_{\mathrm{OH}}\right) ; 1695\left(v_{\mathrm{C}=\mathrm{O}}\right) ; 1647\left(v_{\mathrm{C}=\mathrm{C}}\right) ; 1341,1304,1268,1234$, $1207\left(\delta_{\mathrm{CH}}\right) ; 1141,1075,1050,1029\left(v_{\mathrm{CO}}\right.$ в $\mathrm{C}-\mathrm{O}-\mathrm{C}$ и $\left.\mathrm{C}-\mathrm{OH}\right) ; 981\left(\delta_{=\mathrm{CH}}\right)$.

ИК-спектр 2 (вазелиновое масло, $v$, см$\left.^{-1}\right)$ : $3330\left(v_{\mathrm{OH}}\right) ; 1729\left(v_{\mathrm{C}=\mathrm{O}}\right) ; 1647\left(v_{\mathrm{C}=\mathrm{C}}\right) ; 1340,1303,1262,1232$, $1205\left(\delta_{\mathrm{CH}}\right) ; 1140,1059,1030\left(v_{\mathrm{CO}}\right.$ в $\mathrm{C}-\mathrm{O}-\mathrm{C}$ и $\left.\mathrm{C}-\mathrm{OH}\right) ; 981\left(\delta_{=\mathrm{CH}}\right)$.

ИК-спектр 3 (вазелиновое масло, $v$, см$\left.^{-1}\right)$ : 3600-3120 ( $\left.v_{\mathrm{OH}}\right) ; 1653,1647\left(\delta_{\mathrm{OH}}\right) ; 1337,1302,1247,1205$ $\left(\delta_{\mathrm{CH}}\right) ; 1158,1081,1049,1026$ ( $v_{\mathrm{CO}}$ в С-O-С и С-OH).

ИК-спектр молекулярного комплекса 1 и 3 (вазелиновое масло, $\left.v, \mathrm{~cm}^{-1}\right)$ : $3340\left(v_{\mathrm{OH}}\right) ; 1685\left(v_{\mathrm{C}=\mathrm{O}}\right)$; $1653-1645\left(\delta_{\mathrm{OH}}, v_{\mathrm{C}=\mathrm{C}}\right) ; 1340,1302,1267,1250,1237,1207\left(\delta_{\mathrm{CH}}\right) ; 1157,1081,1050,1030\left(v_{\mathrm{CO}}\right.$ в С-О-С и С$\mathrm{OH}) ; 982\left(\delta_{=\mathrm{CH}}\right)$.

ИК-спектр молекулярного комплекса 2 и 3 (вазелиновое масло, v, см $\left.{ }^{-1}\right)$ : $3330\left(v_{\mathrm{OH}}\right) ; 1729\left(v_{\mathrm{C}=\mathrm{O}}\right)$; $1653-1645\left(\delta_{\mathrm{OH}}, v_{\mathrm{C}=\mathrm{C}}\right) ; 1340,1303,1260,1205\left(\delta_{\mathrm{CH}}\right) ; 1156,1126,1080,1057,1050,1030$ ( $v_{\mathrm{CO}}$ в С-О-С и С$\mathrm{OH}) ; 981\left(\delta_{=\mathrm{CH}}\right)$.

Всхожесть семян Avena sativa L. (Роасеаe (Gramineae)) проверяли в лабораторных условиях при температуре $\left(27-28{ }^{\circ} \mathrm{C}\right)$ по методике, описанной в [13]. Результаты приведены в таблице 1.

Ихтиотоксичность проверяли на рыбах Poecilia reticulata (Poeciliidae) по методике, приведенной в [14]. Рыб (по 10 штук) помещали в $0,25 \cdot 10^{-3} \mathrm{M}$ растворы 1-3, а также в их комплексы, содержащие по $0,25 \cdot 10^{-3} \mathrm{M}$ каждого из компонентов. Определяли время инкубации $t_{L D_{100}}$, в течение которого происходил $100 \%$ летальный исход (табл. 2).

\section{Обсуждение результатов}

Спектральные исследования. Молекула 1 состоит из гидрофобной агликонной части и гидрофильного дисахаридного фрагмента. Она может взаимодействовать как с гидрофобной внутренней полостью, так и гидрофильными торцевыми поверхностями 3, содержащими ОН-группы. Атом С-3 и группа $\mathrm{CH}_{3}$ у C-20 агликона, близкого по структуре к хедерагенину (агликону гликозидов 1 и 2 ), удалены друг от друга на 1,3 нм [8]. Расстояние от атома С-11 до водорода у С-7 менее 0,57 нм [8]. Центральный диаметр внутренней полости тора 3 составляет 0,60-0,65 нм, а его высота - 0,78 нм [15, 16]. Следовательно, геометрические препятствия для расположения части агликона молекулы $\mathbf{1}$ в полости $\mathbf{3}$ отсутствуют. Ранее было показано, что в клатратных комплексах агликонный фрагмент тритерпеновых гликозидов находится в полости циклодекстринов [8, 10]. 
Таблица 1. Прорастание семян Avena sativa L. в лабораторных условиях (концентрации индивидуальных веществ и веществ в комплексе по $0,5 \cdot 10^{-4} \mathrm{M}$ )

\begin{tabular}{|c|c|c|c|c|c|c|}
\hline \multirow[b]{2}{*}{ Параметр } & \multicolumn{6}{|c|}{ Соединение } \\
\hline & $\begin{array}{c}\mathrm{H}_{2} \mathrm{O} \\
\text { (контроль) }\end{array}$ & 1 & 2 & 3 & $\begin{array}{c}\text { Комплекс } \\
1 \text { с } 3\end{array}$ & $\begin{array}{c}\text { Комплекс } \\
2 \text { с } 3\end{array}$ \\
\hline \multicolumn{7}{|c|}{ Через 24 ч } \\
\hline Всхожесть, \% & 52 & 8 & 24 & 32 & 56 & 68 \\
\hline Длина ростка, мм & $0,5 \pm 0,2$ & $0,1 \pm 0,1$ & $0,4 \pm 0,3$ & $0,4 \pm 0,2$ & $1,3 \pm 0,8$ & $1,0 \pm 0,6$ \\
\hline Количество с корнем, \% & 80 & 56 & 64 & 56 & 92 & 100 \\
\hline Длина корня, мм & $0,9 \pm 0,2$ & $0,7 \pm 0,3$ & $1,0 \pm 0,5$ & $0,9 \pm 0,5$ & $2,6 \pm 1,2$ & $2,3 \pm 0,7$ \\
\hline \multicolumn{7}{|c|}{ Через 48 ч } \\
\hline Всхожесть, \% & 76 & 52 & 64 & 72 & 72 & 96 \\
\hline Длина ростка, мм & $3,9 \pm 1,4$ & $0,5 \pm 0,2$ & $1,6 \pm 0,8$ & $2,0 \pm 1,0$ & $5,4 \pm 2,5$ & $4,2 \pm 1,5$ \\
\hline Количество с корнем, \% & 88 & 80 & 76 & 84 & 96 & 100 \\
\hline Длина корня, мм & $2,2 \pm 0,7$ & $1,3 \pm 0,5$ & $2,0 \pm 0,9$ & $2,8 \pm 1,4$ & $7,0 \pm 3,0$ & $6,8 \pm 1,9$ \\
\hline \multicolumn{7}{|c|}{ Через 72 ч } \\
\hline Всхожесть, \% & 92 & 68 & 86 & 80 & 84 & 96 \\
\hline Длина ростка, мм & $7,9 \pm 1,8$ & $1,6 \pm 0,8$ & $3,8 \pm 1,7$ & $6,2 \pm 2,8$ & $12,0 \pm 4,6$ & $9,2 \pm 2,9$ \\
\hline Количество с корнем, \% & 92 & 80 & 84 & 88 & 96 & 100 \\
\hline Длина корня, мм & $7,1 \pm 1,9$ & $1,6 \pm 0,8$ & $2,9 \pm 0,9$ & $7,2 \pm 3,6$ & $11,2 \pm 4,7$ & $9,3 \pm 2,6$ \\
\hline
\end{tabular}

Таблица 2. Ихтиотоксичность гликозидов 1 и 2 и их комплексов с 3 против Poecilia reticulata

\begin{tabular}{c|c|c}
\hline Соединение & $c$, M & $t_{L D_{100}}$ до летального исхода, мин \\
\hline 1 & $0,25 \cdot 10^{-3}$ & $13,0 \pm 1,3$ \\
2 & $0,25 \cdot 10^{-3}$ & Время экспозиции протяжении 120 мин не токсично \\
3 & $0,25 \cdot 10^{-3}$ & На протяжении 120 мин не токсично \\
Комплекс $1-3$ & По $0,25 \cdot 10^{-3}$ каждого вещества & На протяжении 120 мин не токсично \\
Комплекс 2-3 & По $0,25 \cdot 10^{-3}$ каждого вещества & На протяжении 120 мин не токсично \\
\hline
\end{tabular}

При анализе ИК-спектров 1 и его комплекса с 3 в области 3600-3200 см ${ }^{-1}$ было установлено, что в результате комплексообразования у $1 v_{\mathrm{OH}}$ изменяется на $-20 \mathrm{~cm}^{-1}$. Известно, что причиной сдвига полос поглощения ОН-группы является образование водородных связей [17]. Частота поглощения группы $\mathrm{C}=\mathrm{O}$ гликозида 1 в комплексе составляет $1685 \mathrm{~cm}^{-1}$, т.е. наблюдается снижение на $10 \mathrm{~cm}^{-1}$ по сравнению с поглощением индивидуального гликозида. Уменьшение $v_{\mathrm{C}=\mathrm{O}}$ указывает на участие карбоксильной группы гликозида 1 в образовании межмолекулярных водородных связей с 3. Ранее подобные изменения в ИКспектрах наблюдались для группы $\mathrm{C}=\mathrm{O}$ при комплексообразовании 1 [18] и тритерпенового гликозида глицирризиновой кислоты [19].

Отмечено смещение некоторых максимумов поглощения связей $\mathrm{C}-\mathrm{O}$ в группах $\mathrm{C}-\mathrm{O}-\mathrm{C}$ и $\mathrm{C}-\mathrm{OH}$ углеводных остатков 1 и 3, что также указывает на межмолекулярное взаимодействие посредством образования водородных связей. Так, у 1 при комплексообразовании частота поглощения таких связей увеличивается с 1141 до $1157 \mathrm{~cm}^{-1}$ и с 1075 до $1081 \mathrm{~cm}^{-1}$. У 3 для полосы поглощения $1026 \mathrm{~cm}^{-1}$ наблюдается сдвиг на +4 см${ }^{-1}$.

Очевидно, что межмолекулярные водородные связи образуют карбоксильная группа агликона и ОНгруппы углеводной части гликозида 1 с ОН-группами глюкозных остатков 3. Дополнительное связывание обеспечивается гидрофобными и ван-дер-ваальсовыми взаимодействиями агликонной части 1 с гидрофобной полостью 3 , в результате чего незначительно (на 1-3 см ${ }^{-1}$ ) изменяются некоторые частоты поглощения связей С-Н. Таким образом, 1 и 3 образуют комплекс типа «гость - хозяин».

Молекула 2 содержит две гидрофильные углеводные цепи при атомах С-3 и С-28 агликона, которые, очевидно, не позволяют ей проникнуть во внутреннюю гидрофобную полость 3 и образовать клатрат. Водородные связи в этом случае наблюдаются между ОН-группами торцевых поверхностей 3 и ОН-группами моносахаридных остатков 2, что подтверждается ИК-спектроскопией.

Так, при сопоставлении ИК-спектров 2, 3 и их комплекса установлено смещение полос поглощения связей С-О в группах C-O-C и С-ОН. У 2 полоса поглощения при $1140 \mathrm{~cm}^{-1}$ сдвигается на $-14 \mathrm{~cm}^{-1}$. При комплексообразовании полоса поглощения 2 при 1059 см$^{-1}$ сдвигается незначительно, однако наблюдается 
уменьшение ее интенсивности. У 3 частота поглощения $1026 \mathrm{~cm}^{-1}$ увеличивается на $4 \mathrm{~cm}^{-1}$. Для остальных полос поглощения 3 сдвиг составляет только $1-2 \mathrm{~cm}^{-1}$.

Кроме того, отмечены некоторые изменения для полос поглощения, связанных с деформационными колебаниями связей СН. В спектре комплекса у 2 отсутствует полоса поглощения $1232 \mathrm{~cm}^{-1}$. Уменьшилась интенсивность полос поглощения $1262 \mathrm{~cm}^{-1}$ у 2 и $1247 \mathrm{~cm}^{-1}$ у 3. В спектре комплекса эти полосы проявились в области $1260 \mathrm{~cm}^{-1}$.

Биологическая активность. Фитотоксичность. Тритерпеновые гликозиды являются факторами аллелопатического взаимодействия, так как благодаря их токсичности подавляется рост и развитие растений $[20,21]$. Известно, что монодесмозидные тритерпеновые гликозиды, в агликонной части которых имеется свободная (негликозилированная) карбоксильная группа у атома С-17, обладают токсическими свойствами. Напротив, бисдесмозиды, у которых данная карбоксильная группа гликозилирована, обладают низкой токсичностью [22]. Поэтому гликозид 1 на протяжении всего эксперимента в наибольшей степени подавлял всхожесть семян (табл. 1). Через 72 ч после обработки семян растворами бисдесмозидного гликозида 2 и 3 их всхожесть оказалась близкой. Комплекс $\mathbf{1}$ с $\mathbf{3}$ имеет низкую фитотоксичность, что можно объяснить вовлечением его карбоксильной группы в комплексообразование с $\mathbf{3}$. Активности $2, \mathbf{3}$ и комплекса 1 с 3 практически совпадают. Всхожесть семян после действия комплекса гликозида 2 с 3 оказалась наибольшей по сравнению со всеми протестированными соединениями и даже превысила всхожесть в контрольной группе. Следовательно, комплекс 2 с 3 не подавляет всхожесть семян. По сравнению с индивидуальными гликозидами их комплексы с 3 также благоприятно влияли на длину ростка.

Комплексы 1 с 3 и $\mathbf{2}$ с $\mathbf{3}$ также способствовали появлению и росту корней. Под их воздействием доля семян с корнем была максимальной на протяжении всего эксперимента. При этом уже через 24 ч комплекс 1 с 3 вызвал появление корня у 92\% семян, а комплекс $\mathbf{2}$ с $\mathbf{3}$ - у 100\% семян (в контрольной группе только $80 \%$ ). Кроме того, через 72 ч после обработки семян полученным нами ранее комплексом $\mathbf{3}$ с моноаммонийной солью глицирризиновой кислоты наблюдалось появление корня у $96 \%$ семян, а их всхожесть составила 92\% [10]. Таким образом, комплекс 2 с 3 в наибольшей степени способствовал появлению ростков и корней у семян.

Ихтиотоксичность. Наличие свободной группы $\mathrm{COOH}$ у атома С-17 агликона также объясняет высокую ихтиотоксичность гликозида 1 (см. табл. 2). Установлено, что $\mathbf{2}$ и 3 , а также комплексы $\mathbf{1}$ с $\mathbf{3}$ и $\mathbf{2}$ с $\mathbf{3}$ состава 1:1 не проявили токсического действия на рыб гуппи Poecilia reticulata при экспозиции в течение 120 мин. Таким образом, у комплексов $\mathbf{1}$ и $\mathbf{2}$ с $\mathbf{3}$ отсутствует ярко выраженная токсичность. Снижение активности гликозида $\mathbf{1}$, находящегося в комплексе, также можно объяснить участием группы $\mathrm{COOH}$ его агликона во взаимодействии с 3 .

\section{Выводы}

1. Впервые получены молекулярные комплексы 1 и 2 с 3. Они образуются за счет водородных связей и невалентных взаимодействий. Комплексообразование подтверждено ИК-спектроскопически.

2. В отличие от 1, его комплекс с 3 имеет низкую фитотоксичность. Комплекс 2 с 3 не подавляет всхожесть семян. Он в наибольшей степени способствовал появлению ростков (всхожесть $96 \%$ ) и корней у семян (100\%). Комплексы 1 с 3 и 2 с 3 оказались неихтиотоксичными.

\section{Список литературь}

1. Толстикова Т.Г., Толстиков А.Г., Толстиков Г.А. На пути к низкодозным лекарствам // Вестник РАН. 2007. T. 77, №10. C. 867-874.

2. Tolstikova T.G., Khvostov M.V., Bryzgalov A.O. The complexes of drugs with carbohydrate-containing plant metabolites as pharmacologically promising agents // Mini-Reviews in Medicinal Chemistry. 2009. Vol. 9, №11. Pp. 1317-1328.

3. Polyakov N.E., Leshina T.V. Glycyrrhizic acid as a novel drug delivery vector: synergy of drug transport and efficacy // The Open Conference Proceedings Journal. 2011. Vol. 2. Pp. 64-72.

4. Yakovishin L.A., Grishkovets V.I., Schroeder G., Borisenko N.I. Molecular complexation of ivy saponins with some drugs and biologically active substances. Functionalized molecules - synthesis, properties and application. Ed. V.I. Rybachenko. Donetsk, 2010. Ch. 4. Pp. 85-103.

5. Hostettmann K., Marston A. Saponins. Cambridge, 1995. 548 p. 
6. Яковишин Л.А., Вожжова М.А., Кузнецова А.Л., Гришковец В.И. Исследование тритерпеновых гликозидов лекарственного препарата проспан ${ }^{\circledR} / /$ Журнал органічної та фармацевтичної хімії. 2005. Т. 3, вип. 1. С. 57-59.

7. Lutsenko Yu., Bylka W., Matławska I., Darmohray R. Ye. Hedera helix as a medicinal plant // Herba Polonica. 2010. Vol. 56, №1. Pp. 83-96.

8. Tamagaki S., Koide M., Takahashi M., Mizushima T., Ukawa J., Tagaki W. Inhibitory effects of cyclodextrins by inclusion on the catalytic activity of glycyrrhizinate for the hydrolysis of a nonionic ester surfactant // Journal of the Chemical Society, Perkin Transactions 2. 1996. Pp. 1257-1260.

9. Lee P.S., Han J.-Y., Song T.W., Sung J.H., Kwon O.-S., Song S., Chung Y.B. Physicochemical characteristics and bioavailability of a novel intestinal metabolite of ginseng saponin (IH901) complexed with $\beta$-cyclodextrin // International Journal of Pharmaceutics. 2006. Vol. 316, №1-2. Pp. 29-36.

10. Яковишин Л.А. Молекулярный комплекс моноаммонийной соли глицирризиновой кислоты (глицирама) с $\beta$-циклодекстрином // Журнал органічної та фармацевтичної хімії. 2012. Т. 10, вип. 4. С. 71-75.

11. Гришковец В.И., Сидоров Д.Ю., Яковишин Л.А., Арнаутов Н.Н., Шашков А.С., Чирва В.Я. Тритерпеновые гликозиды Hedera canariensis I. Строение гликозидов L-A, L-B, L-B 2 , L-C, L-D, L-E, L-G $_{1}, \mathrm{~L}_{-} \mathrm{G}_{2}, \mathrm{~L}_{-} \mathrm{G}_{3}, \mathrm{~L}_{4} \mathrm{G}_{4}$, L-H ${ }_{1}$, L-H 2 и L-I ${ }_{1}$ из листьев Hedera canariensis // Химия природных соединений. 1996. №3. С. 377-383.

12. Шашков А.С., Гришковец В.И., Лолойко А.А., Чирва В.Я. Тритерпеновые гликозиды Hedera taurica I. Строение таурозида Е из листьев Hedera taurica // Химия природных соединений. 1987. №3. С. 363-366.

13. Яковишин Л.А., Лекарь А.В., Ветрова Е.В., Борисенко Н.И., Гришковец В.И. Молекулярные комплексы тритерпеновых гликозидов с $L$-гистидином и их биологическая активность // Biopolymers and Cell. 2011. Т. 27, №4. С. 300-305.

14. Яковишин Л.А., Борисенко Н.И., Руднев М.И., Ветрова Е.В., Гришковец В.И. Самоассоциация и комплексообразование тритерпеновых гликозидов и холестерина // Химия природных соединений. 2010. № 1. С. 45-48.

15. Steed J.W., Atwood J.L. Supramolecular chemistry. Chichester, 2000. 745 p.

16. Challa R., Ahuja A., Ali J., Khar R.K. Cyclodextrins in drug delivery: an updated review // AAPS PharmSciTech. 2005. Vol. 6, №2. Pp. E329-E357.

17. Казицына Л.А., Куплетская Н.Б. Применение УФ-, ИК-, ЯМР- и масс-спектроскопии в органической химии. M., 1979. $240 \mathrm{c}$.

18. Яковишин Л.А., Гришковец В.И., Корж Е.Н. Молекулярное комплексообразование тритерпеновых гликозидов с аспирином // Ученые записки Таврического национального университета им. В.И. Вернадского. Сер. «Биология, химия». 2012. Т. 25 (64), №2. С. 288-293.

19. Толстиков Г.А., Балтина Л.А., Муринов Ю.И., Давыдова В.А., Толстикова Т.Г., Бондарев А.И., Зарудий Ф.С., Лазарева Д.Н. Комплексы $\beta$-глицирризиновой кислоты с нестероидными противовоспалительными средствами как новые транспортные формы // Химико-фармацевтический журнал. 1991. Т. 25, №2. С. $29-32$.

20. Waller G.R., Jurzysta M., Trohne R.L.Z. Root saponins from alfalfa (Medicago sativa L.) and their allelopathic activity on weeds and wheat // Allelopathy Journal. 1995. Vol. 2, №1. Pp. 21-30.

21. Chaieb I. Saponins as insecticides: a review // Tunisian Journal of Plant Protection. 2010. Vol. 5, №1. Pp. 39-50.

22. Podolak I., Galanty A., Sobolewska D. Saponins as cytotoxic agents: a review // Phytochemistry Reviews. 2010. Vol. 9. Pp. 425-474. 


\section{Yakovishin L.A. MOLECULAR COMPLEXES OF TRITERPENE GLYCOSIDES FROM IVY WITH $\beta$ - CYCLODEXTRIN}

Sevastopol National Technical University, Universitetskaya Str., 33, Sevastopol, 299053 (Russia),

e-mail: chemsevntu@ rambler.ru

Molecular complexes of triterpene glycosides $\alpha$-hederin (hederagenin 3-O- $\alpha$-L-rhamnopyranosyl-( $1 \rightarrow 2)-\mathrm{O}-\alpha-\mathrm{L}-$ arabinopyranoside) and hederasaponin $C$ (hederagenin 3-O- $\alpha$-L-rhamnopyranosyl- $(1 \rightarrow 2)-\mathrm{O}-\alpha-\mathrm{L}-$ arabinopyranosyl-28-O- $\alpha-\mathrm{L}-$ rhamnopyranosyl-( $1 \rightarrow 4)$-O- $\beta$-D-glucopyranosyl- $(1 \rightarrow 6)-\mathrm{O}-\beta$-D-glucopyranoside) with $\beta$-cyclodextrin have been prepared. The complexation has been investigated by FT-IR spectroscopy. The toxic properties of the molecular complexes have been considered. toxicity.

Keywords: triterpene glycosides, $\alpha$-hederin, hederasaponin $\mathrm{C}, \beta$-cyclodextrin, molecular complex, FT-IR-spectroscopy,

\section{References}

1. Tolstikova T.G., Tolstikov A.G., Tolstikov G.A. Vestnik RAN, 2007, vol. 77, no. 10, pp. 867-874. (in Russ.).

2. Tolstikova T.G., Khvostov M.V., Bryzgalov A.O. Mini-Reviews in Medicinal Chemistry, 2009, vol. 9, pp. 1317-1328.

3. Polyakov N.E., Leshina T.V. The Open Conference Proceedings Journal, 2011, vol. 2, pp. 64-72.

4. Yakovishin L.A., Grishkovets V.I., Schroeder G., Borisenko N.I. Functionalized molecules - synthesis, properties and application / ed. V.I. Rybachenko. Donetsk, 2010. Ch. 4. Pp. 85-103.

5. Hostettmann K., Marston A. Saponins. Cambrige, 1995. 548 p.

6. Yakovishin L.A., Vozhzhova M.A., Kuznetsova A.L., Grishkovets V.I. Zhurnal organichnoi ta farmatsevtichnoi khimii, 2005, vol. 3, no. 1, pp. 57-59. (in Russ.)

7. Lutsenko Yu., Bylka W., Matławska I., Darmohray R. Ye. Herba Polonica, 2010, vol. 56, no. 1, pp. 83-96.

8. Tamagaki S., Koide M., Takahashi M., Mizushima T., Ukawa J., Tagaki W. Journal of the Chemical Society, Perkin Transactions 2, 1996, pp. 1257-1260.

9. Lee P.S., Han J.-Y., Song T.W., Sung J.H., Kwon O.-S., Song S., Chung Y.B. International Journal of Pharmaceutics, 2006, vol. 316, no. 1-2, pp. 29-36.

10. Yakovishin L.A. Zhurnal organichnoi ta farmatsevtichnoi khimii, 2012, vol. 10, no. 4, pp. 71-75. (in Russ.)

11. Grishkovets V.I., Sidorov D.Yu., Yakovishin L.A., Arnautov N.N., Shashkov A.S., Chirva V.Ya. Khimiia prirodnykh soedinenii, 1996, no. 3, pp. 377-383. (in Russ.)

12. Shashkov A.S., Grishkovets V.I., Loloyko A.A., Chirva V.Ya. Khimiia prirodnykh soedinenii, 1987, no. 3, pp. 363366. (in Russ.)

13. Yakovishin L.A., Lekar A.V., Vetrova E.V., Borisenko N.I., Grishkovets V.I. Biopolymers and Cell, 2011, vol. 27, no. 4, pp. 300-305. (in Russ.)

14. Yakovishin L.A., Borisenko N.I., Rudnev M.I., Vetrova E.V., Grishkovets V.I. Khimiia prirodnykh soedinenii, 2010, no. 1, pp. 45-48. (in Russ.)

15. Steed J.W., Atwood J.L. Supramolecular chemistry. Chichester, 2000. 745 p.

16. Challa R., Ahuja A., Ali J., Khar R.K. AAPS PharmSciTech, 2005, vol. 6, no. 2, pp. E329-E357.

17. Kazitsyna L.A., Kupletskaia N.B. Primenenie UF-, IK-, IaMR- $i$ mass-spektroskopii v organicheskoi khimii. [Application of UV, IR, NMR and mass spectroscopy in organic chemistry]. Moscow, 1979, 240 p. (in Russ.)

18. Yakovishin L.A., Grishkovets V.I., Korzh E.N. Uchenye zapiski Tavricheskogo natsional'nogo universiteta im. V.I. Vernadskogo. Ser. Biologiia, khimiia, 2012, vol. 25, no. 2, pp. 288-293. (in Russ.)

19. Tolstikov G.A., Baltina L.A., Murinov Yu.I., Davydova V.A., Tolstikova T.G., Bondarev A.I., Zarudy F.S., Lazareva D.N. Khimiko-Farmatsevticheskii Zhurnal, 1991, vol. 25, no. 2, pp. 29-32. (in Russ.)

20. Waller G.R., Jurzysta M., Trohne R.L.Z. Allelopathy Journal, 1995, vol. 2, no. 1, pp. 21-30.

21. Chaieb I. Tunisian Journal of Plant Protection, 2010, vol. 5, no. 1, pp. 39-50.

22. Podolak I., Galanty A., Sobolewska D. Phytochemistry Reviews, 2010, vol. 9, pp. 425-474. 